\title{
Lens capsule-related problems in patients undergoing phacoemulsification surgery
}

This article was published in the following Dove Press journal:

Clinical Ophthalmology

8 March 2013

Number of times this article has been viewed

\section{Lokman Aslan \\ Adnan Aksoy \\ Murat Aslankurt \\ Murat Özdemir \\ Ophthalmology Department, Faculty of Medicine, Kahramanmaraș Sutcu Imam University, Kahramanmaraș, Turkey}

Correspondence: Lokman Aslan Department of Ophthalmology, Faculty of Medicine, Kahramanmaraș

Sutcu Imam University,

46100 Kahramanmaraș, Turkey

Tel +90 5326069808

Fax +903442212371

Email lokaslan46@yahoo.com
Purpose: This study aimed to compare lens capsule-related problems in mature versus nonmature senile cataracts in patients undergoing phacoemulsification surgery.

Methods: A total of 295 patients with senile cataract were divided into two groups according to lens maturation: 105 patients with mature senile cataract comprised Group 1 (study group) and the remaining 190 with non-mature senile cataract comprised Group 2 (control group). Prior to surgery, ophthalmological examination was undertaken. Patients' best-corrected visual acuity and intraocular pressure were measured and a slit-lamp examination and funduscopy performed. All examination data were recorded and any capsule-related problems during surgery were also recorded. Patient files were reviewed retrospectively and compared between groups. Fisher's exact test was used in the statistical analysis.

Results: In Group 1, the capsule-related problems found were: inability to complete capsulorhexis (seven eyes [6.6\%]), posterior capsular perforation (three eyes [2.8\%]), and conversion to extracapsular surgery (one eye $[0.9 \%]$ ). A posterior capsular perforation was seen in one eye $(1 \%)$ in the control group. An intraocular lens was inserted into the sulcus in six eyes $(5.7 \%)$ and one anterior chamber $(0.9 \%)$ in Group 1 and into the sulcus in one eye $(0.5 \%)$ of Group 2. The lens was inserted into the capsular bag in all other patients.

Conclusion: Delaying surgery in patients with cataracts creates a high risk for capsule-related surgical complications. Although capsule dyes make capsulorhexis easier, capsulorhexis is the most problematic phase of phacoemulsification in mature cataracts.

Keywords: mature senile cataract, non-mature senile cataract, capsulorhexis

\section{Introduction}

Cataract is one of the most common causes of treatable blindness, especially in developing countries. ${ }^{1}$ The prevalence of cataract in the world varies according to age and geographic area. ${ }^{1}$ In recent years, cataract surgery has become safer and more effective due to surgical innovations; ${ }^{2}$ however, phacoemulsification (PE), the currently preferred surgical technique, is indicated more for early stage cataract than previous techniques. ${ }^{3}$ Although PE is safe and effective, there are difficulties in implementing this procedure in patients with advanced cataract, which is a serious problem in patients of poor socioeconomic status in developing countries who have delayed having surgery. , $^{4}$ Changes can occur in the lens capsule and the lens contents of a mature cataract over time. These changes make it difficult to perform surgical procedures. ${ }^{5-7}$ One of the most significant problems is changes in the lens capsule. ${ }^{8}$

The lens capsule is a transparent basal membrane that contains structural elements of the lens and epithelial cells and fibers that surround and protect the lens. ${ }^{1}$ It differs 
from other basal membranes in the body in that it continuously thickens. The anterior capsule, measuring $8 \mu \mathrm{m}$ thick at birth, may thicken with increasing age to $14 \mu \mathrm{m} .{ }^{1,9}$ Patients with advanced cataract frequently have capsular fibrosis, adhesions, calcification, and weakness of the zonules. ${ }^{3,9}$ In addition, advanced lens density prevents the red fundus reflex produced by the coaxial light of the microscope, making it difficult to differentiate the edge of the anterior capsule from the underlying white lens matter. In these cases, applying pressure on the lens capsule during capsulorhexis can cause irregular capsule rupture because of the increased and liquefied lens material. When the capsule is first pierced, milky liquefied cortical matter can leak into and thus obscure the view of the anterior chamber. ${ }^{10,11}$ Previous surgical techniques that did not require capsulorhexis to be completed generated fewer complications than PE. However, proper capsulorhexis is necessary for seamless PE surgery. ${ }^{9,11}$

In the study reported here, we aimed to compare surgical problems caused by the lens capsule in patients with mature versus non-mature senile cataracts.

\section{Materials and methods}

A total of 295 eyes of 295 patients who underwent cataract surgery in our clinic were included in this retrospective study. The study was approved by the ethics committee of our university and conducted according to the tenets of the Declaration of Helsinki. Informed consent was obtained from all of patients for the surgical procedure and data collection. Exclusion criteria were traumatic cataract, infection, glaucoma, and uveitis.

Full ocular examination - including determination of best-corrected visual acuity, intraocular pressure measurement, slit-lamp examination, funduscopy, ultrasound, and biometry - was undertaken prior to surgery. Patients were divided into two groups according to maturation of the lens. The first group (study group) had white mature cataract, determined according to the Lens Opacities Classification System III criteria. The second group (control group) had non-mature senile cataract.

All cataract surgeries were performed by one surgeon (LA). Cyclopentolate $1 \%$ and phenylephrine $10 \%$ eye drops were instilled to dilate the pupils before surgery. The eyes and surrounding adnexa were cleansed using 5\% and 10\% povidone-iodine solution, respectively. A clear corneal incision was made and continuous, curvilinear capsulorhexis was performed. Trypan blue was used as capsule dye to allow the anterior capsule to be seen in the mature cataract group but not in the control group. PE equipment (AMO WhiteStar
Signature ${ }^{\circledR}$ Phaco System, Abbott Medical Optics, Santa Ana, CA, USA) was used in the surgery. The nucleus was acquired with quick chop and PE. Irrigation and aspiration were performed for cortical material. An acrylic foldable intraocular lens (Ocuva A625, VSY Biotechnology, Istanbul, Turkey) was inserted into the capsular bag, under the side port irrigation. An intracameral antibiotic ( $1 \mathrm{mg} / 0.1 \mathrm{~mL}$, Cefuroxime axetil) was applied into the anterior chamber at the end of the surgery. Topical corticosteroid eye drops (dexamethasone $0.1 \%$ ) and antibiotic eye drops (ciprofloxacin $0.3 \%$ ) were used postoperatively by patients six times per day for the following 2 weeks.

Any capsulorhexis problems and surgical complications occurring during surgery were recorded. All the data obtained for the two groups were compared. Fisher's exact test was used for the statistical analysis.

\section{Results}

\section{Patient characteristics}

In Group $1(\mathrm{n}=105), 105$ eyes of 59 female and 46 male patients with mature cataract stage 4 were operated on. The mean age of patients in this group was $69.93 \pm \mathrm{SD} 8.60$ (range 40-88) years old. In Group $2(n=190), 91$ eyes of 96 females and 94 males with senile cataract were operated on. The mean age of patients in this group was $67.42 \pm 8.4$ (range 47-84) years old (Table 1). In Group 1, visual acuity was light perception to counting fingers. The mean intraocular pressure in this group was $14.22 \pm 3.14$ (range 10-26) mmHg. In Group 2, mean visual acuity was $0.34 \pm 0.25$ Snellen units (range $0.05-0.50)$ and mean intraocular pressure was $14.06 \pm 2.90$ (10-24) $\mathrm{mmHg}$.

The capsule-related problems found during cataract surgery (PE) were: inability to complete capsulorhexis in seven eyes $(6.6 \%)$ of seven patients (four female and three male, mean age $72.71 \pm 5.20$ years old), posterior capsular perforation in three eyes $(2.8 \%)$, (two female and one male, mean age $77.33 \pm 6.11$ years) and conversion to extracapsular cataract extraction in one eye $(0.9 \%)$ (female, 84 years old) in the mature cataract group (Group 1). Posterior capsular perforation was encountered as a complication in

Table I The distribution of the demographic structure of patients

\begin{tabular}{lll}
\hline & First group & Second group \\
\hline Male, $\mathrm{n}(\%)$ & $46(44)$ & $94(49)$ \\
Female, $\mathrm{n}(\%)$ & $59(56)$ & $96(5 \mathrm{I})$ \\
Total, $\mathrm{n}(\%)$ & $105(100)$ & $190(100)$ \\
Age, years & $69.93 \pm 8.6^{*}$ & $67.42 \pm 8.4$ \\
\hline
\end{tabular}

Note: $* \pm$ : SD. 
one eye $(0.5 \%)$ (female, 72 years old) in the control group. Of the patients in whom capsule problems were detected, one had a Morgagnian cataract, four had white mature cataract, and two had corticonuclear cataract.

An intraocular lens was inserted into the sulcus in six eyes $(5.7 \%)$ and one anterior chamber $(0.9 \%)$ in Group 1 and into the sulcus in one eye $(0.5 \%)$ in Group 2. Lenses were inserted into the capsular bag in all other patients (Table 2).

Compared with the control group, surgical problems occurred more often in the mature cataract group, and the difference between the two groups in this regard was statistically significant $(P<0.05)$ for the capsulorhexis stage. In terms of posterior capsular perforation, the difference between the two groups was not statistically significant $(P=0.347)$. For intraocular lens placement in mature cataract, anterior chamber and sulcus placement occurred at a high rate, and was statistically significant for sulcus placement $(P<0.05)$.

\section{Discussion}

The current cataract surgery technique of choice, which has developed over time, is PE. Unlike with previous methods, its widespread use and the increasing surgical experience of its practitioners have reduced the indication time for cataract surgery. Previously used surgical procedures were invasive and the healing process was long, ${ }^{12-15}$ so they were more suitable for advanced-stage cataract. However, even though these techniques did not require capsulorhexis to be completed, thus resulted in fewer problems, PE requires capsulorhexis to be completed, meaning there is more risk of surgical complication. Capsulorhexis failure has been shown to have a negative impact on surgical success in mature cataract because of lens capsule changes. ${ }^{14,15}$

Thickening and calcification of the lens capsule and high pressure applied by the lens material to the capsule make it difficult to undertake capsulorhexis. The capsule is friable and tends to escape to the periphery during capsulorhexis.

Table 2 Capsule-related problems and intraocular lens placement results in Group I, patients with mature cataract $(n=105)$, and Group 2, patients with non-mature cataract $(n=190)$

\begin{tabular}{|c|c|c|c|}
\hline & $\begin{array}{l}\text { Group I, } \\
\text { n (\%) }\end{array}$ & $\begin{array}{l}\text { Group 2, } \\
\text { n (\%) }\end{array}$ & $\mathbf{P} *$ \\
\hline Capsulorhexis not completed & $7(6.6)$ & $0(0)$ & $<0.05$ \\
\hline Posterior capsule perforation & $3(2.8)$ & $\mathrm{I}(0.5)$ & 0.552 \\
\hline \multicolumn{4}{|l|}{ Intraocular lens insertion } \\
\hline Sulcus & $6(5.7)$ & I (0.5) & $<0.05$ \\
\hline Anterior chamber & I (0.9) & $0(0)$ & 0.644 \\
\hline Capsular bag & $98(93)$ & $189(99.4)$ & \\
\hline
\end{tabular}

Note: *Determined using Fisher's exact test.
In such cases, rhexis can progress to the posterior capsule easily. Sometimes, PE must be converted to extracapsular cataract extraction with extended corneal incision. ${ }^{15-21}$ In mature cataract cases, the anterior chamber can be created with a dense viscoelastic device to overcome the tension on the capsule. To do this, the anterior capsule is perforated with a sharp cystotome then capsulorhexis is performed. Further, in mature cataracts, sometimes fundus reflexes cannot be seen because the anterior capsule obscures them. To resolve this difficulty, capsule dyes have been developed. ${ }^{22-24}$ In our study, we used trypan blue as the capsule dye in the mature cataract surgeries performed. Trypan blue, allowing us to see the capsule, made the process capsulorhexis easier. We were unable to complete capsulorhexis in seven mature cataract patients and, in one case, extracapsular surgery was performed. Three patients had rupture of the posterior capsule at the same time. The appropriate capsulorhexis was performed in all patients in the control group. The capsule dye was not needed in these patients as their anterior capsule was easily seen.

With mature cataracts, lens changes play an important role during capsulorhexis. The increased lens volume applies pressure on the anterior capsule, making capsulorhexis difficult. ${ }^{25-31}$ When the capsule is pierced, milky cortex material can spill over into the anterior chamber and hamper visibility of the anterior capsule. In addition, discharge of the milky cortex material diminishes on pressure to the lens capsule, so capsulorhexis becomes more difficult. In such cases, pressure balance can be achieved by adding a viscoelastic substance to the capsular bag and anterior chamber before proceeding with capsulorhexis. In the control group, the pressure exerted on the capsule was stable after viscoelastic was inserted into the anterior chamber, allowing capsulorhexis to be performed easily.

\section{Conclusion}

In mature cataract cases, changes to the lens and capsule make it difficult to perform capsulorhexis and increase the risk of surgical complications when the PE technique is used. To reduce complications and increase surgical success in future, the obstacles preventing patients from having cataract surgery early must be determined and resolved.

\section{Disclosure}

The authors declare no conflicts of interest in this work.

\section{References}

1. Kanski JJ. Disorder of lens. The lens. In: Clinical Ophthalmology: A Systematic Approach, 4th ed. Oxford: Butterworth-Heinemann; 1999:157-182. 
2. Ermisş SS, Oztürk F, Inan UU. Comparing the efficacy and safety of phacoemulsification in white mature and other types of senile cataracts. Br J Ophthalmol. 2003;87(11):1356-1359.

3. Brazitikos PD, Tsinopoulos IT, Papadopoulos NT, Fotiadis K, Stangos NT. Ultrasonographic classification and phacoemulsification of white senile cataracts. Ophthalmology. 1999;106(11):2178-2183.

4. Bozkurt E, Yazııı AT, Sarışın E, Bozkurt S, Kevser MA, Yılmaz ÖF. Early results of cataract interventions in Niger Tesseoua region. Glokom-Katarakt. 2007;2(3):193-195. Turkish.

5. Bajimaya S, Sharma BR, Shrestha JB, Maharjan IM, Matsushima H, Akura J. Phacoemulsification surgery by a nationally-trained cataract surgeon of Nepal. Nepal J Ophthalmol. 2012;4(8):248-255.

6. Podhorecki J, Munir A. Result of operations for hyper-mature cataract complicated with phacolytic glaucoma. Klin Oczna. 2002;104(5-6): 350-353. Polish.

7. Zare M, Javadi MA, Einollahi B, Baradaran-Rafii AR, Feizi S, Kiavash V. Risk factors for posterior capsule rupture and vitreous loss during phacoemulsification. J Ophthalmic Vis Res. 2009;4(4): 208-212.

8. Johansson B, Lundström M, Montan P, Stenevi U, Behndig A. Capsule complication during cataract surgery: Long-term outcomes: Swedish Capsule Rupture Study Group report 3. J Cataract Refract Surg. 2009; 35(10):1694-1698.

9. Gavriş M, Popa D, Cărăuş C, Gusho E, Kantor E. Phacoemulsification in white cataract. Oftalmologia. 2004;48(2):81-87. Romanian.

10. Jakobsson G, Montan P, Zetterberg M, Stenevi U, Behndig A, Lundström M. Capsule complication during cataract surgery: retinal detachment after cataract surgery with capsule complication: Swedish Capsule Rupture Study Group report 4. J Cataract Refract Surg. 2009; 35(10):1699-1705.

11. Vajpayee RB, Bansal A, Sharma N, Dada T, Dada VK. Phacoemulsification of white hypermature cataract. J Cataract Refract Surg. 1999;25(8):1157-1160.

12. Venkatesh R, Tan CS, Sengupta S, Ravindran RD, Krishnan KT, Chang DF. Phacoemulsification versus manual small-incision cataract surgery for white cataract. J Cataract Refract Surg. 2010;36(11): 1849-1854.

13. Mehta KR, Mehta CK. Surgery for brunescant and black cataracts. In: Buratto L, Osher R, Masket S, editors. Cataract Surgery in Complicated Cases. Thorofare, NJ: Slack; 2000:44-46.

14. Küchle M, Schönherr U, Dieckmann U. Risk factors for capsular rupture and vitreous loss in extracapsular cataract extraction. The Erlangen Ophthalmology Group. Fortschr Ophthalmol. 1989;86(5):417-421. German.
15. Venkatesh R, Das M, Prashanth S, Muralikrishnan R. Manual small incision cataract surgery in eyes with white cataracts. Indian J Ophthalmol. 2005;53(3):173-176.

16. Singh R, Vasavada AR, Janaswamy G. Phacoemulsification of brunescent and black cataracts. J Cataract Refract Surg. 2001;27(11):1762-1769.

17. Vasavada A, Singh R. Surgical techniques for difficult cataracts. Curr Opin Ophthalmol. 1999;10(1):46-52.

18. Cakir H, Utine CA. Lift and crack technique for risky cataract cases. J Cataract Refract Surg. 2010;36(4):539-541.

19. Ashraf KM. Primary posterior capsular opacification in hypermature white cataracts. J Cataract Refract Surg. 2010;36(12):2211-2212.

20. Chan E, Mahroo OA, Spalton DJ. Complications of cataract surgery. Clin Exp Optom. 2010;93(6):379-389.

21. Czumbel N, Albert A. Cataract surgery (phacoemulsification) in difficult cases. Oftalmologia. 2009;53(4):41-44.

22. Burkholder BM, Srikumaran D, Nanji A, Lee B, Weinberg RS. Inadvertent trypan blue posterior capsule staining during cataract surgery. Am J Ophthalmol. Epub December 6, 2012.

23. Jacob S, Agarwal A, Agarwal A, et al. Trypan blue as an adjunct for safe phacoemulsification in eyes with white cataract. J Cataract Refract Surg. 2002;28(10):1819-1825.

24. Portes AL, Almeida AC, Allodi S, Monteiro ML, Miguel NC. Trypan blue staining for capsulorhexis: ultrastructural effect on lens epithelial cells and capsules. J Cataract Refract Surg. 2010;36(4):582-587.

25. Hameed AS, Alkhatib TK, Rageh MA, et al. Yemeni experience with phacoemulsification. Saudi Med J. 2009;30(5):687-692.

26. Ilavska M, Kardos L. Phacoemulsification of mature and hard nuclear cataracts. Bratisl Lek Listy. 2010;111(2):93-96.

27. Odugbo OP, Mpyet CD, Chiroma MR, Aboje AO. Cataract blindness, surgical coverage, outcome, and barriers to uptake of cataract services in Plateau State, Nigeria. Middle East Afr J Ophthalmol. 2012; 19(3):282-288.

28. Carifi G. Oval capsulorhexis and its advantages. J Cataract Refract Surg. 2012;38(1):184-185.

29. Susić N, Brajković J, Susić E, Kalauz-Surać I. Phacoemulsification in eyes with white cataract. Acta Clin Croat. 2010;49(3):343-345.

30. Kolawole OU, Ashaye AO, Mahmoud AO, Adeoti CO. Cataract blindness in Osun state, Nigeria: results of a survey. Middle East Afr J Ophthalmol. 2012;19(4):364-371.

31. Yazici AT, Bozkurt E, Kara N, Yildirim Y, Demirok A, Yilmaz OF. Long-term results of phacoemulsification combined with primary posterior curvilinear capsulorhexis in adults. Middle East Afr J Ophthalmol. 2012;19(1):115-119.
Clinical Ophthalmology

\section{Publish your work in this journal}

Clinical Ophthalmology is an international, peer-reviewed journal covering all subspecialties within ophthalmology. Key topics include: Optometry; Visual science; Pharmacology and drug therapy in eye diseases; Basic Sciences; Primary and Secondary eye care; Patient Safety and Quality of Care Improvements. This journal is indexed on Submit your manuscript here: http://www.dovepress.com/clinical-ophthalmology-journal

\section{Dovepress}

PubMed Central and CAS, and is the official journal of The Society of Clinical Ophthalmology (SCO). The manuscript management system is completely online and includes a very quick and fair peer-review system, which is all easy to use. Visit http://www.dovepress.com/ testimonials.php to read real quotes from published authors. 